\title{
$4(83) / 2016$
}

INFORMATSIONNO-

UPRAVLIAIUSHCHIE SISTEMY

REFEREED EDITION (INFORMATION AND CONTROL SYSTEMS)

Founder

«Information and Control Systems», Ltd.

Publisher

Saint-Petersburg State University

of Aerospace Instrumentation

Editor-in-Chief

M. Sergeev

Dr. Sc., Tech., Professor, St. Petersburg, Russia

Deputy Editor-in-Chief

E. Krouk

Dr. Sc., Tech., Professor, St. Petersburg, Russia

Executive secretary

O. Muravtsova

Editorial Council

C. Christodoulou

PhD, Professor, Albuquerque, New Mexico, USA

L. Chubraeva

RAS Corr. Member, Dr. Sc., Tech., Professor, St. Petersburg, Russia L. Fortuna

PhD, Professor, Catania, Italy

A. Fradkov

Dr. Sc., Tech., Professor, St. Petersburg, Russia

V. Kozlov

Dr. Sc., Tech., Professor, St. Petersburg, Russia

B. Meyer

Dr. Sc., Professor, Zurich, Switzerland

A. Ovodenko

Dr. Sc., Tech., Professor, St. Petersburg, Russia

Y. Podoplyokin

Dr. Sc., Tech., Professor, St. Petersburg, Russia

Yu. Shokin

RAS Academician, Dr. Sc., Phys.-Math., Novosibirsk, Russia

V. Simakov

Dr. Sc., Tech., Professor, Moscow, Russia

V. Vasilev

RAS Corr. Member, Dr. Sc., Tech., Professor, St. Petersburg, Russia

R. Yusupov
RAS Corr. Member, Dr. Sc., Tech., Professor, St. Petersburg, Russia

Editorial Board

V. Anisimov

Dr. Sc., Tech., Professor, St. Petersburg, Russia

B. Bezruchko

Dr. Sc., Phys.-Math., Saratov, Russia

N. Blaunstein

Dr. Sc., Phys.-Math., Professor, Beer-Sheva, Israel

A. Dudin

Dr. Sc., Tech., Professor, Minsk, Belarus

I. Dumer

PhD., Professor, Riverside, USA

V. Khimenko

Dr. Sc., Tech., Professor, St. Petersburg, Russia

G. Maltsev

Dr. Sc., Tech, Professor, St. Petersburg, Russia

G. Matvienko

Dr. Sc., Phys.-Math., Professor, Tomsk, Russia

V. Melekhin

Dr. Sc., Tech., Professor, St. Petersburg, Russia

A. Shalyto

Dr. Sc., Tech., Professor, St. Petersburg, Russia

A. Shelupanov

Dr. Sc., Tech., Professor, Tomsk, Russia

A. Shepeta

Dr. Sc., Tech., Professor, St. Petersburg, Russia

A. Smirnov

Dr. Sc., Tech., Professor, St. Petersburg, Russia

Z. Yuldashev

Dr. Sc., Tech., Professor, St. Petersburg, Russia

A. Zeifman

Dr. Sc., Phys.-Math., Vologda, Russia

Editor: A. Larionova

Proofreader: T. Zvertanovskaia

Design: N. Karavaeva, M. Chernenko

Layout and composition: N. Karavaeva, J. Umnitsina

Contact information

The Editorial and Publishing Center, SUAI
67 , B. Morskaia, 190000, St. Petersburg, Russia

67, B. Morskaia, 190000, St. Petersburg, Russia

Website: http://i-us.ru/en,
Tel.: +7 - 8124947002

The Journal was registered in the Ministry of Press,

Broadcasting and Mass Media of the Russian Federation

Registration Certificate JD № 77-12412 from April, 19, 2002 .

Re-registration in the Federal Service for Supervision in the Sphere of Telecom,

Information Technologies and Mass Communications (ROSKOMNADZOR)

due to change of the founder: "Information and Control Systems", Ltd.,

JD № FS77-49181 from March, 30, 2012.

(c) Corporate authors, 2016

THEORETICAL AND APPLIED MATHEMATICS

Balonin N. A., Jennifer Seberry. Cretan $(4 t+1)$ Matrices

INFORMATION AND CONTROL SYSTEMS

Kashevnik A. M., Baraniuc O. A., Gordeev B. R. Competency

Management System for Technoparks

Michurin S. V., Ivakin Ya. A. The Effectiveness and Quality of Situational

Management Software for Automated Dispatching of Air Transport Spatial

Processes

SYSTEM AND PROCESS MODELING

Balonin N. A., Sergeev M. B., Suzdal V. S. Matrix Models of Generalized

Crystallography

Maltsev G. N., Nazarov A. V., Yakimov V. L. Simulation Modeling of

Diagnostics of a Highly Autonomous Complex Technical System

Pyataeva A. V., Favorskaya M. N. Background Model for Video-Based Smoke Detection in Outdoor Scenes

Tregybov R. B., Oreshin A. N. Traffic Source Model with Changeable Transmission Rate

Solov'eva T. N., Perevaryukha A. Yu. Dynamic Model of Depletion of Sturgeon Stocks with Complex Intrapopulation Structure

HARDWARE AND SOFTWARE RESOURCES

Shpakov V. M. Computer Implementation of Processes on the Base of Their Logic-Dynamic Specification

INFORMATION SECURITY

Abramov M. V., Azarov A. A., Tulupyeva T. V., Tulupyev A. L. Model of Malefactor Competencies Profile for Analyzing Information System

Personnel Security from Social Engineering Attacks

STOCHASTIC DYNAMICS AND CHAOS

Khimenko V. I. Scatterplots in Analysis of Random Streams of Events

INFORMATION CHANNELS AND MEDIUM

Pavlov V. S. Spatial-Frequency Method for Estimating Angular Coordinates of a Radar Object

Koucheryavy Y. A., Yartsev S. V. Epidemic Theory as a Tool for Analysis of Broadcasting Process in VANET

INFORMATION ABOUT THE AUTHORS

Submitted for publication 04.07.16. Passed for printing 22.08.16. Format $60 \times 84_{1 / 8}$ Offset paper. Phototype SchoolBookC. Offset printing.

Layout original is made at the Editorial and Publishing Center, SUAI. 67, B. Morskaia, 190000, St. Petersburg, Russia Center, SUA 67, B. Morskaia, 190000, St. Petersburg, Russia

The journal is distributed by subscription. Subscription can be made in the Editorial and publishing center, SUAl as well as in any post office based on «Rospechat" catalogue 


\section{$4(83) / 2016$}

ИНФОРМАЦИОННОУПРАВЛЯЮЩИЕ

\section{РЕЦЕНЗИРУЕМОЕ ИЗДАНИЕ}

\section{СИСТЕМЫ}

Учредитель

ООО «Информационно-управляющие системы»

Издатель

Санкт-Петербургский государственный университет

аэрокосмического приборостроения

Главный редактор

М. Б. Сергеев,

д-р техн. наук, проф., С.-Петербург, РФ

Зам. главного редактора

E. A. Крук

д-р техн. наук, проф., С.-Петербург, РФ

Ответственный секретарь

О. В. Муравцова

Редакционный совет:

Председатель А. А. Оводенко,

д-р техн. наук, проф., С.-Петербург, РФ

В. Н. Васильев,

чл.-корр. РАН, д-р техн. наук, проф., С.-Петербург, РФ

В. Н. Козлов,
Д-р техн. наук, проф., С.-Петербург, РФ

К. Кристодолу

д-р наук, проф., Альбукерке, Нью-Мексико, США

Б. Мейер,

Д-р наук, проф., Цюрих, Швейцария

Ф. Подоплёкин

д-р техн. наук, проф., С.-Петербург, РФ

В. В. Симаков,

д-р техн. наук, проф., Москва, РФ

Л. Фортуна,

д-р наук, проф., Катания, Италия

А. Л. Фрадков,

Д-р техн. наук, проф., С.-Петербург, РФ

Л. И. Чубраева,

чл.-корр. РАН, д-р техн. наук, С.-Петербург, РФ

О. И. ШОКИН,

акад. РАН, д-р физ.-мат. наук, проф., Новосибирск, РФ

Р. М. Юсупов

чл.-корр. РАН, д-р техн. наук, проф., С.-Петербург, РФ

Редакционная коллегия:

В. Г. Анисимов,

д-р техн. наук, проф., С.-Петербург, РФ

Б. П. Безручко

д-р физ.-мат. наук, проф., Саратов, РФ

Н.Блаунштейн,

д-р физ.-мат. наук, проф., Беэр-Шева, Израиль

А. Н. Дудин,

д-р физ.-мат. наук, проф., Минск, Беларусь

И. И. Думер

д-р наук, проф., Риверсайд, США

А. И. Зейфман,

д-р физ.-мат. наук, проф., Вологда, РФ

Г. Н. Мальцев,

Д-р техн. наук, проф., С.-Петербург, РФ

Г. Г. Матвиенко

д-р физ.-мат. наук, проф., Томск, РФ

В. Ф. Мелехин,

д-р техн. наук, проф., С.-Петербург, РФ

А. В. Смирнов,

д-р техн. наук, проф., С.-Петербург, РФ

В.И. Хименко

д-р техн. наук, проф., С.-Петербург, РФ

А. А. Шалыто

д-р техн. наук, проф., С.-Петербург, РФ

А. А. Шелупанов,

д-р техн. наук, проф., Томск, РФ

А. П. Шепета,

д-р техн. наук, проф., С.-Петербург, РФ

3. М. Юлдашев

д-р техн. наук, проф., С.-Петербург, РФ

ТЕОРЕТИЧЕСКАЯ И ПРИКЛАДНАЯ МАТЕМАТИКА

Balonin N. A., Jennifer Seberry. Cretan $(4 t+1)$ Matrices

ИНФОРМАЦИОННО-УПРАВЛЯЮЩИЕ СИСТЕМЫ

Кашевник А. М., Баранюк О. А., Гордеев Б. Р. Система управления компетенциями резидентов технопарков

Мичурин С. В., Ивакин Я. А. Результативность и качество

программных комплексов ситуационного управления для автоматизированных систем диспетчеризации

пространственных процессов авиатранспорта

\section{МОДЕЛИРОВАНИЕ СИСТЕМ И ПРОЦЕССОВ}

Балонин Н. А., Сергеев М. Б., Суздаль В. С. Матричные модели обобщенной кристаллографии

Мальцев Г. Н., Назаров А. В., Якимов В. Л. Имитационное моделирование процесса диагностирования сложной технической системы с высоким уровнем автономности функционирования

Пятаева А. В., Фаворская М. Н. Модель фона при детектировании дыма по видеопоследовательностям на открытых пространствах

Трегубов Р. Б., Орешин А. H. Модель источника трафика с изменяющейся скоростью передачи

Соловьева Т H Переварюха А. Ю. Динамическая модель деградации запасов осетровых рыб со сложной внутрипопуляционной структурой

ПРОГРАММНЫЕ И АППАРАТНЫЕ СРЕДСТВА

Шпаков В. М. Компьютерная реализация процессов на основе их логико-динамической спецификации

\section{ЗАЩИТА ИНФОРМАЦИИ}

Абрамов М. В., Азаров А. А., Тулупьева Т. В., Тулупьев А. Л. Модель профиля компетенций злоумышленника в задаче анализа защищённости персонала информационных систем от социоинженерных атак

СТОХАСТИЧЕСКАЯ ДИНАМИКА И ХАОС

Хименко В. И. Диаграммы рассеяния в анализе случайных потоков событий

\section{ИНФОРМАЦИОННЫЕ КАНАЛЫ И СРЕДЫ}

Павлов В. С. Пространственно-частотный метод определения угловых координат локационного объекта

Кучерявый E. A., Ярцев С. В. Теория эпидемий как инструмент анализа распространения широковещательного трафика в сетях VANET

\section{СВЕДЕНИЯ ОБ АВТОРАХ}

Редактор: А. Г. Ларионова

Корректор: Т. В. Звертановская

Дизайн: Н. Н. Караваева, М. Л. Черненко

Компьютерная верстка: Н. Н. Караваева, Ю. В. Умницына

Адрес редакции: 190000 , Санкт-Петербург,

Б. Морская ул., д. 67, ГУАП, РИЦ

Тел.: (812) 494-70-02, e-mail: ius.spb@gmail.com, сайт: http://i-us.ru

Журнал зарегистрирован в Министерстве РФ по делам печати, телерадиовещания и средств массовых коммуникаций.

Свидетельство о регистрации ПИ № 77-12412 от 19 апреля 2002 г.

Свидетельство о регистрации ПИ № ФС77-49181 от 30 марта 2012 г.

Журнал входит в «Перечень ведущих рецензируемых научных журналов и изданий, в которых должны быть опубликованы основные научные результаты диссертации на соискание ученой степени доктора и кандидата наук».

(๑) Коллектив авторов, 2016

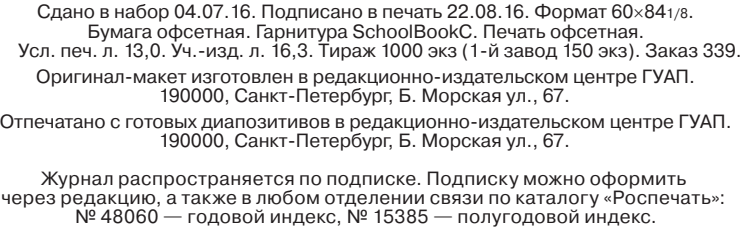

